\title{
Efecto de la cobertura del suelo con cascarilla de arroz en el crecimiento y rendimiento del tomate de ramillete
}

\author{
Gisela Rodríguez Rodríguez \\ Instituto de Investigaciones Hortícolas Liliana Dimítrova \\ Carretera Bejucal-Quivicán, km 33 1⁄2. Quivicán, La Habana, Cuba. CP 33500
}

\begin{abstract}
G. Rodríguez Rodríguez. 2007. Effect of rice bran mulching on growth and yield of cherry tomato. Cien. Inv. Agr. 34(3):225-230. From the spring to fall of 2005, in northern Kanto, located in central Japan, an open field was prepared for cultivating cherry tomatoes (Lycopersicon esculentum var. cerasiforme) with three types of mulch: 1 . Rice straw with rice bran, 2. Rice straw alone, and 3. Polyethylene film covering. The fruits were harvested from June to the end of September. There were significant differences between the treatments in both the total yield of fruit $(p=0.0379)$ as well as in the yield of normal fruit $(p=0.0458)$. The highest total fruit production $\left(3.4 \mathrm{~kg} \cdot\right.$ plant $\left.^{-1}\right)$ was obtained with the rice straw and bran treatment, followed by the other two treatments, with about $2.5 \mathrm{~kg} \cdot \mathrm{plant}^{-1}$. Other factors, such as total fruit number and the weight of damaged fruit, were not significantly different. Forty days after planting in the field, plant height and other vegetative characteristics were measured; no statistically significant differences between the studied soil treatments were observed. These results indicate that the application of rice bran on a field surface previously covered with rice straw contributed to an increase in the yields of the tomato plants. The application of rice bran also facilitated weed control management.
\end{abstract}

Key words: Cherry tomato, Lycopersicon esculentum, organic mulch, rice bran mulch, rice straw mulch.

\section{Introducción}

El tomate (Lycopersicon esculentum Mill) es uno de los vegetales más importantes y populares del mundo (Peralta y Spooner, 2002). En Cuba, ocupa aproximadamente 60.000 ha anualmente. También se considera la especie hortícola más importante en Asia, con alrededor de 25 millones de toneladas métricas producidas anualmente en cerca de un millón de hectáreas (Hanson y Chen, 1996). China es el líder mundial en producción de tomate con alrededor del $25 \%$ de la producción mundial (FAO, 2005).

Existen tres tipos de tomate, cultivares para consumo fresco, para uso industrial y tomate

Recibido 18 abril 2007. Aceptado 31 agosto 2007.

'Dirigir correspondencia a G. Rodríguez: grroguez@yahoo.com.mx de ramillete (tomate cherry). El grupo de los tomates de ramilletes ( $L$. esculentum var. cerasiforme (Dunal) A. Gray) es de frutos pequeños que asemejan cerezas y se pueden hacer cosechas sucesivas desde la misma planta. El tomate cherry se considera ancestro de los tomates actuales (Lorenz y Maynard, 1980). Recientemente, los tomates de pequeña talla se popularizaron en el trópico. Estos tienen un gran potencial de cultivo, siendo muy atractivos por su apariencia, sabor y como fuente importante de vitaminas y minerales. Tienen bajo contenido en grasas y son altos en contenido de azúcares (Gómez et al., 2000).

Los factores más importantes que reducen la productividad del tomate son las altas temperaturas, alta humedad, exceso de precipitaciones, plagas y enfermedades (Opeña, 1985). Por el contrario, la cobertura del suelo (mulch) es un factor importante en el control 
de malezas y conservación de la humedad, lo que permite mantener un ambiente favorable para el desarrollo de raíces, manteniendo la temperatura uniforme. Esto acelera la maduración de los frutos (Saijapongese et al., 1989). La distribución de la humedad en la capa arable de un suelo cubierto es más uniforme, comparada con un suelo descubierto. En un suelo cubierto se promueve el desarrollo de raíces en la capa arable, estrato rico en nutrientes y donde abundan microorganismos beneficiosos (Lippert y Takatori, 1964).

La cobertura orgánica, con residuos de plantas como paja y hierbas, mejora los rendimientos en tomates y además incorpora materia orgánica al suelo, lo que mejora la calidad del mismo (Wilson, 1979). Los altos rendimientos bajo cobertura se deben al incremento en el número de racimos, flores, frutos por planta y rendimientos precoces (Gómez et al., 1997). Este trabajo tuvo por objetivo evaluar el efecto de diferentes tipos de cobertura del suelo sobre el rendimiento y calidad del tomate de ramillete.

\section{Materiales y métodos}

\section{Cultivo}

El experimento se realizó en condiciones de campo en el Centro Internacional de Entrenamientos de Tsukuba, Tsukuba, Japón, entre febrero y septiembre de 2005. Se usó tomate cv. Sweet Chelsea (Sakata Seeds. Co. Ltd. 2000, Tokio, Japón), híbrido $F_{1}$ de tomate de tipo indeterminado. Se injertó sobre el híbrido $\mathrm{F}_{1}$ 'Magnet' (Sakata Seeds. Co. Ltd.). Se usaron dos tipos de injerto, el Super-With e injerto en aguja (injerto pin) (Sakata Seed Co, Ltd., 20012002). El primero consistió en cortar el tallo de la plántula sobre las hojas cotiledonales en un ángulo de 25 a $30^{\circ}$, cortar el material a injertar en el mismo ángulo y con una presilla pegar ambos cortes hasta conseguir su cicatrización. El injerto de aguja consistió en cortar el porta injerto en ángulo recto e introducir la aguja dentro del tallo en el material a injertar (Takii Seed Co. Ltd., 2003, Kyoto, Japón).

El híbrido 'Sweet Chelsea' tiene alta tolerancia a craqueo y rajadura y mantiene su calidad en estantería. El híbrido 'Magnet' tiene resistencia a la marchitez bacteriana (Ralstonia solanacearum), nematodo agallador (Meloidogyne incognita), al virus del mosaico del tabaco (TMV) y tolerancia a la podredumbre blanda (Erwinia carotovora subs. carotovora) (Katsumi, 1995).

La fertilización se realizó de forma basal con $20 \mathrm{t}^{\mathrm{h}} \mathrm{a}^{-1}$ de compost, $1,5 \mathrm{t} \cdot \mathrm{ha}^{-1}$ de dolomita y 6,75 g.planta ${ }^{-1}$ de Bokashi (mezcla descompuesta y fermentada de compost, cascarilla de arroz molida, harina de pescado y agua). Se hizo una segunda aplicación de Bokashi, 18 g.hilera ${ }^{-1}$, y de cascarilla de arroz molida (4 $\mathrm{kg}$ por parcela) en el tratamiento de salvado y paja (T1), a los 50 días de transplantado en el campo.

En el transcurso del experimento hubo una infestación con moscas blancas (Bemisia tabaci) y trips (Thrips palmi) en los estados tempranos del desarrollo del cultivo, pero posterior a la formación del primer racimo. Estas plagas se controlaron con vinagre de madera $\left(2 \mathrm{~mL} \cdot \mathrm{L}^{-1}\right.$ de agua), leche entera diluida al $50 \%$ y extracto líquido de ají picante $\left(3,4 \mathrm{~mL} \cdot \mathrm{L}^{-1}\right.$ de agua).

La temperatura del aire y precipitaciones se registraron en el lugar de ensayo (Tsukuba Meteorological Centre, febrero-octubre, 2005).

\section{Tratamientos}

Se evaluaron los siguientes materiales vegetales como cobertores del suelo: 1. Cobertura con salvado y paja de arroz (T1, Salvado y paja). 2. Cobertura con paja de arroz (T2, Paja) y 3. Cobertura plástica consistente en un film de polietileno, blanco por encima y negro por dentro (T3, Control de plástico). La cobertura con paja de arroz y la cobertura plástica se aplicaron nueve días antes de transplante (18 de abril).

\section{Evaluación}

El efecto de cada tratamiento se evaluó en 108 plantas en total, por medio de los siguientes parámetros: 1. Altura de la planta a los 40 días después de trasplantado. 2. Número de racimos, clasificados estructuralmente en racimos con botones, con flores, con flores y frutos y con solamente frutos. 3. Tamaño de los frutos en 
el primer racimo, clasificados de acuerdo con estándares de 22,5 y 26,5 cm de diámetro. 4 . Se cosechó dos veces por semana, desde el 13 de junio hasta el 26 de septiembre. Se determinó el peso de los frutos comercializables y no comercializables, debido a la presencia de daños o malformaciones.

\section{Diseño y análisis estadísticos}

Las parcelas experimentales fueron de 3,6 x 1,2 $\mathrm{m}\left(4,32 \mathrm{~m}^{2}\right)$, compuestas por dos hileras de seis plantas cada una con 36 plantas por tratamiento. La distancia entre plantas y entre hileras fue 60 cm. El área total usada en el ensayo fue 97,2 $\mathrm{m}^{2}$. Los tratamientos se distribuyeron conforme con un diseño de bloques completos al azar, con tres repeticiones. Se realizó análisis de varianza y los promedios se separaron por la prueba de comparación múltiple de Bonferroni.

\section{Resultados y discusión}

\section{Altura de la planta}

Las plantas del tratamiento T1, con salvado y paja, fueron ligeramente más altas $(96,75$ $\mathrm{cm}$ ), seguido del tratamiento T3 (plástico) con
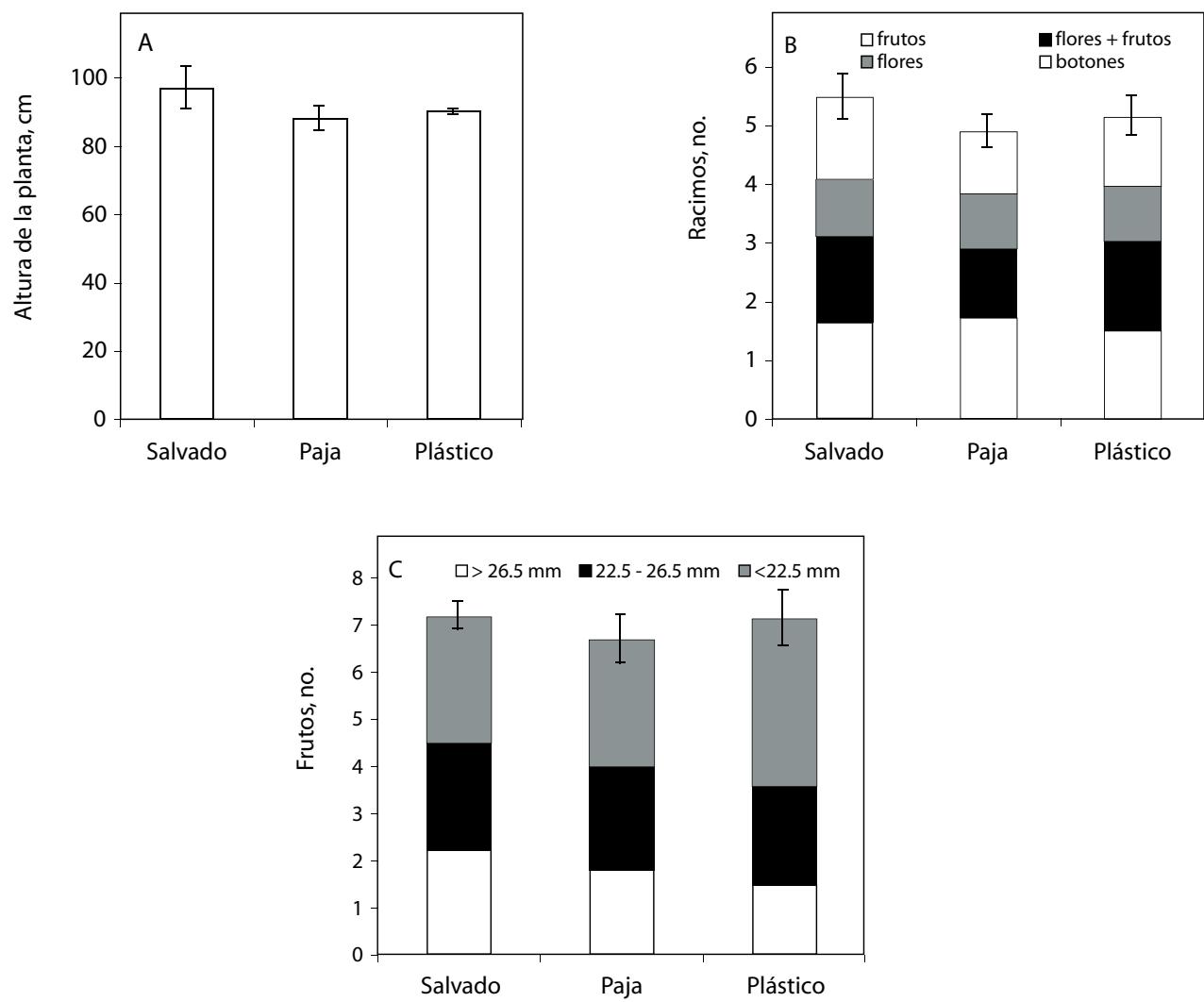

Figura 1. Comportamiento de diferentes parámetros en plantas de tomate de ramillete (tomate cherry) (Lycopersicon esculentum var. cerasiforme) cv. Sweet Chelsea injertadas sobre tomate cv. Magnet, determinado 40 días después de la plantación. Diferencias no significativas a p $<0,05$. Barras verticales indican error estándar. A. Altura de la planta. B. Número de racimos por planta. C. Número y tamaño de frutos. Salvado, cobertura con salvado y paja de arroz. Paja, cobertura con paja de arroz. Plástico, cobertura plástica consistente en un film de polietileno, blanco por encima y negro por dentro (tratamiento control).

Figure 1. Behavior of different parameters in $\mathrm{c} v$. Sweet Chelsea cherry tomato plants (Lycopersicon esculentum var. cerasiforme) grafted onto cv. Magnet tomato plants, determined 40 days after planting. Differences not significant at $p<$ 0.05. Vertical bars indicate standard error. A. Plant height. B. Number of clusters per plant. C. Number and size of fruit. Bran, rice straw and bran mulch. Straw, rice straw mulch. Plastic, plastic covering consisting of a polyethylene film, white on top and black underneath (treatment control). 
$89,92 \mathrm{~cm}$ y el tratamiento T2 (paja) con 87,97 $\mathrm{cm}$ (Figura 1A). Sin embargo, los resultados del análisis estadístico no mostraron diferencias significativas entre tratamientos $(\mathrm{p}=0,24)$.

\section{Racimos}

En el número de racimos clasificados según su estado, el tratamiento T1 con salvado y paja fue ligeramente superior con 5,47 racimos totales, seguido de los tratamientos T3 (plástico) y T2 (paja), con 5,14 y 4,89 racimos respectivamente. Sin embargo, el análisis de varianza no fue significativo (Figura 1B). Resultados similares reportaron Vandenberge y Tiessen (1973), indicando el efecto positivo que ejercen las coberturas con polietileno y papel sobre el crecimiento y floración del tomate.

\section{Tamaño de los frutos}

La medida del tamaño de los frutos del híbrido Sweet Chelsea fue ligeramente mayor que la moneda de 500 yenes $(26,5 \mathrm{~mm})$, empleada como referencia. No hubo diferencias significativas entre los tratamientos para el total de frutos cosechados $(\mathrm{p}=0,81)$; pero éstos, fueron más grandes en el tratamiento T1 (salvado y paja) que los otros tratamientos (Figura 1C).

\section{Rendimiento}

Se efectuaron 27 cosechas en total, dos veces por semana entre el 13 de junio y el 26 de septiembre, con una duración de 106 días. El peso promedio de frutos normales y dañados se presenta en la Figura 5. Hubo un efecto estadísticamente significativo $(p=0,038)$ de los tratamientos de cobertura sobre el peso total (frutos normales + dañados), siendo también significativos $(p=0,046)$ el efecto cobertura sobre en el peso de frutos normales.

El tratamiento $\mathrm{T} 1$ con salvado de arroz fue significativamente superior a los otros dos tratamientos de cobertura estudiados (Figura 2). El rendimiento de frutos normales en el tratamiento $\mathrm{T} 1$ fue de $3,35 \mathrm{~kg} \cdot$ planta $^{-1}$. Los rendimientos en los tratamientos con paja de arroz y cobertura plástica fueron similares con alrededor de 2,6 kg.planta ${ }^{-1}$. Los frutos dañados fueron observados fundamentalmente después de las lluvias y el principal síntoma fue craqueo y partiduras.

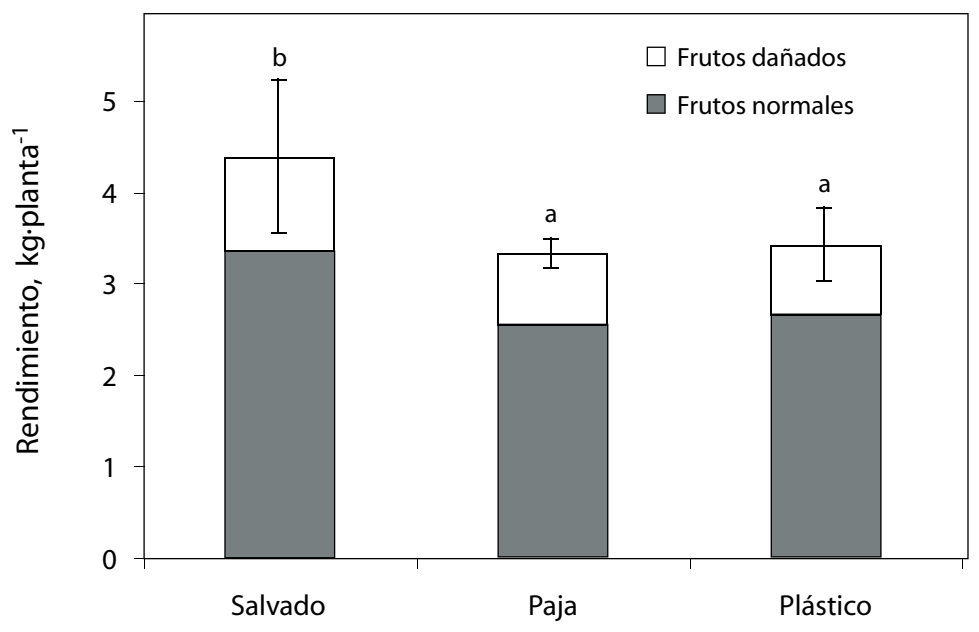

Figura 2. Efecto de la cobertura con salvado de arroz (salvado), paja de arroz (paja) y polietileno blanco y negro (plástico) sobe el rendimiento de los frutos de tomate de ramillete (tomate cherry) (Lycopersicon esculentum var. cerasiforme) cv. Sweet Chelsea injertados sobre Magnet. Letras diferentes indican diferencias estadísticamente significativas según la prueba de comparación múltiple de Bonferoni $(\mathrm{p}=0,05)$. Barras = desviación estándar.

Figure 2. Effect of mulching with rice bran (bran), rice straw (straw), and white and black polyethylene (plastic) on the yield of fruit in $\mathrm{cv}$. Sweet Chelsea cherry tomatoes (Lycopersicon esculentum var. cerasiforme) grafted on Magnet. Different letters indicate statistically significant differences according to Bonferoni's multiple comparison test $(p=0.05)$. Bars $=$ standard deviation . 


\section{Número de frutos}

En el número total de frutos normales y dañados por planta durante el tiempo de cosecha, no hubo diferencias estadísticamente significativas entre los tratamientos de cobertura en estudio. La cantidad de frutos normales en el tratamiento $\mathrm{T} 1$ (salvado paja) fue levemente mayor en cantidad de frutos (132 frutos totales por planta) que los obtenidos en los tratamientos (108 y 116 frutos, respectivamente). También el número de frutos dañados fue mayor en el tratamiento con salvado (T1)(50 frutos). Esto coincidió con lo planteado por Siborlabane (2000) donde apuntó que el rendimiento y la calidad de los frutos de tomate para el mercado fresco varían en función del tipo de cobertera que se use en la plantación.

Se observó que los frutos más grandes fueron más susceptibles al craqueo que los pequeños. Esto concuerda con Snapp (2004) quien plantea que el craqueo de los frutos aparece usualmente en frutos maduros de gran tamaño. Según Snapp (2004), la máxima calidad de los frutos de tomate para el mercado fresco depende de las condiciones de producción de este cultivo.

Según Gómez et al. (1997), el empleo de coberturas del suelo (mulch in situ) constituye un método promisorio para la producción temprana de tomate a campo abierto en Cuba. El establecimiento del mismo favorece el control de malezas, disminuye los daños por bacteriosis en los frutos (Xanthomonas campestris pv. vesicatoria) e incrementa el rendimiento comercial hasta $33 \mathrm{t} \cdot \mathrm{ha}^{-1}$.

Los resultados obtenidos en este trabajo indican que el uso de cascarilla de arroz (salvado) tuvo un efecto significativo sobre los rendimientos de tomate de ramillete cv. Sweet Chelsea. Es importante destacar que a excepción del rendimiento, este tratamiento fue similar al uso de polietileno como cobertura, tratamiento del suelo comúnmente empleado. No obstante, a diferencia del uso de polietileno las coberturas orgánicas tiene como ventaja el aporte de materia orgánica al suelo.

\section{Resumen}

En la primavera al otoño del año 2005, en el norte de Kanto, localizado en el centro de Japón se preparó un área de campo para cultivar tomate de ramillete (tomate cherry) (Lycopersicon esculentum var. cerasiforme) con tres tipos de cobertura: 1. Paja de arroz con salvado de arroz, 2. Paja de arroz solamente y 3. Cobertura con polietileno. La cosecha de los frutos se realizó desde junio hasta finales de septiembre. Hubo diferencias significativas entre los tratamientos, en el rendimiento total de los frutos $(\mathrm{p}=$ $0,0379)$ y el de frutos normales ( $p=0,0458$ ). Las mayores producciones de frutos totales $(3,4$ $\mathrm{kg} \cdot$ planta $\left.^{-1}\right)$ se obtuvieron con el tratamiento de paja de arroz con salvado de arroz, seguido por los otros dos tratamientos con alrededor de 2,5 $\mathrm{kg} \cdot$ planta $^{-1}$. Los otros factores como el total de frutos y el peso de frutos dañados no fueron significativamente diferentes. Después de 40 días de sembrado en el campo, se midió la altura de la planta y otros caracteres vegetativos sin obtener diferencias estadísticamente significativas entre los tratamientos del suelo estudiados. Los resultados indican que la aplicación de salvado de arroz en la superficie del campo previamente cubierto con paja de arroz, para las plantas de tomate, contribuyen al incremento de los rendimientos. La aplicación de salvado de arroz, también redujo el manejo para el control de malezas.

Palabras claves: Cobertura orgánica, Lycopersicon esculentum, mulch de paja de arroz, mulch de salvado de arroz, tomate cherry, tomate enano.

\section{Literatura citada}

FAO. 2005. FAOSTAT. http://faostat.fao.org. (Consultado el 14 de enero, 2007).

Gómez,O.,A.Casanova,L.Martínez,J.C.Hernández, G. de Armas, R. Santos y A. Hernández. 1997. Principales resultados científicos en Hortalizas y papa. Cultivo del tomate. Memorias 25 Aniversario del Instituto de Investigaciones Hortícolas “Liliana Dimitrova”. Cuba. p. 11-19.

Gómez, O., A. Casanova, H. Laterrot y G. Anaïs. 2000. Mejora genética y manejo del cultivo del tomate para la producción en el Caribe. Instituto de Investigaciones Hortícolas "Liliana Dimitrova", La Habana. 159 p.

Hanson, P.M., and J. Chen. 1996. AVRDC's Tomato Improvement Project. AVRDC (Asian Vegetable Research Development Centre) Newsletter 1: 5-8. 
Katsumi, O. 1995. Diseases of tropical vegetable crops. MAFF. Association for International Cooperation of Agriculture and Forestry. Japan. pp 2-17.

Lippert, L.F., and F.H. Takotori. 1964. Soil moisture under bands of petroleum and polyethylene mulches. Journal of the American Society for Horticultural Science 67:541-546.

Lorenz, O.A., and D.N. Maynard. 1980. Knott's Handbook for Vegetable Growers Second ed. John Wiley and Sons. NY, USA. p. 390.

Opeña, R.T. 1985. Development of tomato and Chinese cabbage cultivars adapted to the hot and humid tropics. Acta Horticulturae 153:521536.

Peralta, I.E., Spooner, D.M. 2007. History, origin and early cultivation of tomato (Solanaceae). In: Razdan, M. K. and Mattoo, A. K. editors. Genetic Improvement of Solanaceous Crops, Vol. 2. Enfield, USA: Science Publishers. p. 1-27.

Saijapongese, A.Y., Y.C. Roam Ota, and C.L. Wu. 1989. Some aspects of cultural management in tomatoes at AVRDC. Pages 349-357. In: T.D. Griggs (ed.). Tomato and Pepper Production in the Tropic. Proceeding of the International Symposium on Integrated Management Practices. Asian Vegetable Research and Development Centre, Shanhua, Tainan, Taiwan.

Siborlabane, Ch. 2000. Effect of Mulching on Yield and Quality on Fresh Market Tomato. Pages 15. In: Training Report 2000. Training Course in Vegetable Production and Research. ARCAVRDC. Nakhon Pathom, Thailand.

Snapp, S. 2004. Maximizing fruit quality in fresh market tomatoes. Department of Horticulture, Michigan State University, Minnesota Fruit and Vegetable. IPM News 1 (14):sn.

Wilson, G.F. 1979. The effects of in situ mulch on tomato production. Pages 182-184. In: R. Cowell (ed.). Proceeding of the 1st International Symposium on Tropical Tomato. Asian Vegetable Research and Development Centre. Shanhua, Tainan, Taiwan. 


\title{
Desinfección de cariopses y regeneración de plantas de Spartina argentinensis
}

\author{
Mirian S. Bueno ${ }^{1}$, Susana R. Feldman ${ }^{1,2}$ y Juan P. Ortiz \\ ${ }^{1}$ Cátedra de Biología, Facultad de Ciencias Agrarias, Universidad Nacional de Rosario, C.C. 14, s2125zaa \\ Zavalla, Argentina. ${ }^{2}$ Consejo de Investigaciones de la Universidad Nacional de Rosario (CIUNR). ${ }^{3}$ Cátedra \\ de Química Biológica. Consejo Nacional de Investigaciones Científicas y Técnicas (CONICET).
}

\begin{abstract}
M.S. Bueno, S.R. Feldman, and J.P. Ortiz. 2007. Cariopsis disinfection and plant regeneration of Spartina argentinensis. Cien. Inv. Agr. 34(3): 231-236. A protocol for disinfection and in vitro regeneration of Spartina argentinensis was developed. The lowest percentage of contamination was obtained after treating caryopses with $90^{\circ}$ ethanol for $60 \mathrm{~s}$ and 20 min immersion in $2.5 \%$ sodium hypochlorite $(\mathrm{NaOCl})$ plus $0.1 \%$ Tween 20 . Murashige and Skoog (MS) media was used for callus induction, supplemented with $0.5 \mathrm{mg} \cdot \mathrm{L}^{-1}$ of 2 , 4 dichlorophenoxy acetic (2,4-D) and $1 \mathrm{mg} \cdot \mathrm{L}^{-1}$ of indole-3-acetic acid (IAA). The highest proportion (20\%) of shoot regeneration was achieved with MS media plus $0.25 \mathrm{mg} \cdot \mathrm{L}^{-1}$ of bencyl aminopurine (BAP), whereas $0.5 \mathrm{mg} \cdot \mathrm{L}^{-1}$ naphtalenacetic acid (NAA) was used for root induction. Plants were regenerated via organogenesis. To our knowledge, this is the first report of a protocol for in vitro plant regeneration of S. argentinensis, and it is the initial stage required for obtaining somaclonal variations.
\end{abstract}

Key words: In vitro regeneration, organogenesis, Spartina.

\section{Introducción}

El espartillo, Spartina argentinensis Parodi (Poaceae: Chloridaeae), es una de las especies dominantes de las comunidades halófilas de distintas áreas de Argentina. Forma matas de altura variable, de 0,5-1,4 m de altura. Aunque produce abundantes panojas durante el verano, se reproduce principalmente en forma agámica por rizomas (Feldman, 2003).

Los espartillares se utilizan para cría de ganado vacuno, a pesar del alto grado de lignificación de sus hojas, lo que reduce la digestibilidad. La obtención de líneas de espartillo caracterizadas por un menor contenido de lignina es una de las alternativas para mejorar la digestibilidad del forraje y al mismo tiempo mejorar la oferta forrajera en las áreas dónde esta especie se encuentra presente.

Recibido 13 junio 2007. Aceptado 05 septiembre 2007.

1Dirigir correspondencia a M. S. Bueno: mbueno@unr.edu.ar
Estudios previos (Larkin y Scowcroft, 1981) demostraron que durante las sucesivas mitosis que se producen en cultivo in vitro pueden ocurrir importantes modificaciones genéticas en las células. Algunas se manifiestan como mutaciones heredables, generando variaciones somaclonales. Por consiguiente, el cultivo de tejidos es una herramienta útil para el mejoramiento de especies vegetales y se ha utilizado en especies forrajeras nativas (Echenique et al., 2001; Kothari et al., 2005).

La elección del explante es fundamental para el establecimiento de un cultivo in vitro (Roca y Mroginsky, 1991). En gramíneas se ha regenerado plantas utilizando embriones inmaduros, inflorescencias inmaduras y cariopses maduros (Dutta Grupta et al., 1999; Echenique et al., 2001). Sin embargo, algunos de estos explantes sólo se pueden obtener en determinadas épocas del año. En el género Spartina, se ha logrado regenerar plantas a partir de cultivo in vitro de cariopses maduros 
(Li et al., 1995, Li and Gallager, 1996; Wang et al., 2003). Sin embargo, en S. argentinensis, la contaminación de sus cariopses por Alternaria alternata, Fusarium graminearum y Bipolaris sorokiniana y otros hongos dificulta la utilización de los mismos para iniciar los cultivos. Algunos de estos hongos se han descrito como endógenos (Feldman et al., 2004). Este trabajo tuvo como objetivo estudiar diferentes tratamientos de desinfección de cariopses de espartillo ( $S$. argentinensis) y evaluar su potencial de regeneración in vitro.

\section{Materiales y métodos}

Se trabajó con cariopses maduros de S. argentinensis, sin pálea ni lemma, extraídos de panojas cosechadas en un espartillar ubicado en Pérez, provincia de Santa Fe, Argentina ( $32^{\circ} 45^{\prime}$ $\left.\mathrm{S} ; 60^{\circ} 35^{\prime} \mathrm{W}\right)$. Se realizaron dos experimentos de desinfección de cariopses: 1. Inmersión durante 20 min en hipoclorito de sodio $\mathrm{NaOCl}$ al 1,5 y $2,5 \%$ (v/v) (Cloro Argentina S.A., $5,5 \mathrm{~g} \cdot \mathrm{L}-1$ de cloro) con o sin el agregado de Tween 20 (0,1\%). 2. Inmersión en $\mathrm{NaOCl}$ 2,5\% con Tween $20(0,1 \%)$ durante 20 o $30 \mathrm{~min}$ a temperatura ambiente con o sin inmersión en etanol $90^{\circ}$ por $60 \mathrm{~s}$. Se utilizaron cinco repeticiones por tratamiento, con 20 cariopses por repetición. Luego de cada tratamiento, los cariopses se lavaron con abundante agua estéril y se los sembró en placas de Petri con medio Murashigue Skoog (MS 1962), sin hormonas, suplementados con $30 \mathrm{~g} \cdot \mathrm{L}^{-1}$ de sacarosa, $7 \mathrm{~g} \cdot \mathrm{L}^{-1}$ de agar, pH 5,8. Los cultivos se incubaron en oscuridad a $23 \pm 2^{\circ} \mathrm{C}$ durante 30 días.

La proporción de cariopses contaminados a los 7 días de la siembra in vitro se evaluó mediante análisis de varianza (ANDEVA) y los promedios se separaron según Duncan (Statistica 5.0). Previo a los análisis, los valores porcentuales se transformaron en arcoseno $\sqrt{ } \mathrm{x}$.

Los cariopses libres de contaminación se transfirieron a tubos de ensayo de $20 \mathrm{ml}$ con diferentes medios para la inducción de callos (Cuadro 1) y se mantuvieron en oscuridad a $25^{\circ} \mathrm{C}$, durante 30 días. Los callos producidos se repicaron a medios para la inducción de vástagos con diferentes concentraciones de bencil amino purina (BAP) y se incubaron a $25^{\circ} \mathrm{C}$, con un fotoperíodo de $16 \mathrm{~h}$ (Cuadro 1 ). Los vástagos obtenidos se separaron y la regeneración de raíces se obtuvo en medio con ácido naftalen acético (ANA) (Cuadro 1).

Las frecuencias de formación de callos y vástagos para los distintos medios ensayados, se compararon mediante prueba de homogeneidad con aplicación de Chi cuadrado $\left(\lambda^{2}\right)$ (SAS Institute, Cary, NC, EUA).

Se realizaron estudios histológicos para determinar la vía de regeneración de los explantes. Las muestras se fijaron en FAA (10\% formol, 5\% ácido acético, 50\% etanol y $35 \%$ agua) y posteriormente se deshidrataron en concentraciones ascendente de etanol (1 $\mathrm{h}$ en cada una de las siguientes soluciones de etanol: $70^{\circ} ; 80^{\circ} ; 90^{\circ}, 96^{\circ}$ y $30 \mathrm{~min}$ en $100^{\circ}$ ). Previo a la inclusión en parafina, las muestras se clarificaron con xilol, realizando un paulatino desplazamiento del etanol $100^{\circ}$ por el xilol. Se realizaron cortes con micrótomo tipo Minot (18$20 \mu \mathrm{m}$ de espesor) y se colorearon con safranina (30 min) y fast-green (60 s), que tiñe de color azul-verdoso las zonas celulósicas y de color fucsia a las zonas lignificadas (Johansen, 1940, Dizeo de Strittmater, 1979). Los preparados montados con bálsamo de Canadá, se observaron y se fotografiaron con microscopio óptico.

Cuadro 1. Composición de los medios de cultivo utilizados para inducción de callos (M), inducción de vástagos (V) y enraizamiento (R) de Spartina argentinensis.

Table 1. Composition of the media used for callus induction $(M)$, shoot $(V)$ and root $(R)$ regeneration of Spartina argentinensis.

\begin{tabular}{lcccc}
\hline \multirow{2}{*}{ Medios } & \multicolumn{4}{c}{ Reguladores de crecimiento ${ }^{1}, \mathrm{mg}^{2} \mathrm{~L}^{-1}$} \\
\cline { 2 - 5 } & $2,4-\mathrm{D}$ & $\mathrm{BAP}$ & $\mathrm{ANA}$ & $\mathrm{AIA}$ \\
\hline Inducción de callos: & & & \\
M1 & 0,5 & 0,05 & 1,00 & \\
M2 & 0,5 & & & 1,00 \\
M3 & 0,5 & 0,05 & & \\
\hline Inducción & de vástagos: & & \\
V1 & & 0,25 & \\
V2 & & 0,50 & \\
\hline Enraizamiento: & & & \\
R & & 0,50 & \\
\hline
\end{tabular}

${ }^{1}$ BAP, 6-bencil amino purina; ANA, ácido naftalén acético; AIA, ácido indol acético; 2,4-D, ácido dicloro fenoxi acético. 


\section{Resultados y discusión}

La desinfección de los explantes con $\mathrm{NaOCl}$ más $0.1 \%$ de Tween 20 como humectante disminuyó significativamente $(\mathrm{p}=0,001)$ la contaminación a los 7 días de incubación. No hubo respuesta diferencial a las concentraciones de $\mathrm{NaOCl}$, posiblemente debido al marcado efecto del humectante que permitió una eficiente desinfección aún con la menor concentración de $\mathrm{NaOCl}$ (Figura 1).

Lacontaminación disminuyó significativamente $(\mathrm{p}<0,05)$ en función del tiempo de inmersión en $\mathrm{NaOCl}$ y con el tratamiento con etanol, sin manifestarse interacción entre las variables analizadas (Figura 2). A diferencia de reportes previos, los mejores resultados se obtuvieron utilizando una mayor concentración de etanol $90^{\circ}$ (Li y Gallagher, 1996). Posiblemente esto se debió a que los cariopses de $S$. argentinensis presentan mayor contaminación fúngica (Feldman et al., 2004).
La presencia de callos se observó a los 7 días de incubación de los explantes en los medios de inducción. En la Figura 3 se observa la evolución porcentual de producción de callos durante los primeros cuarenta días de cultivo. La obtención de callos fue máxima a los 30 días de iniciado el cultivo, estabilizándose posteriormente. No se detectaron diferencias estadísticas significativas en las frecuencias de inducción de callos entre los medios M1 y M2 (68,8 y 62,5\% respectivamente), respuesta coincidente con los resultados obtenidos previamente para S. alterniflora (Wang et al., 2003). La inducción de callos sólo alcanzó a $37,5 \%$ en el medio 3 , que incluyó $0,5 \mathrm{mg} \cdot \mathrm{L}^{-1}$ de 2,4-D y $0,05 \mathrm{mg} \cdot \mathrm{L}^{-1}$ de BAP, debido a la ausencia de ANA o AIA.

Los estudios histológicos mostraron que la regeneración de vástagos ocurrió vía organogénesis, donde se observa la formación de dos vástagos dentro de la masa del callo, sin zonasembriogénicas ni proembriones(Figura5).

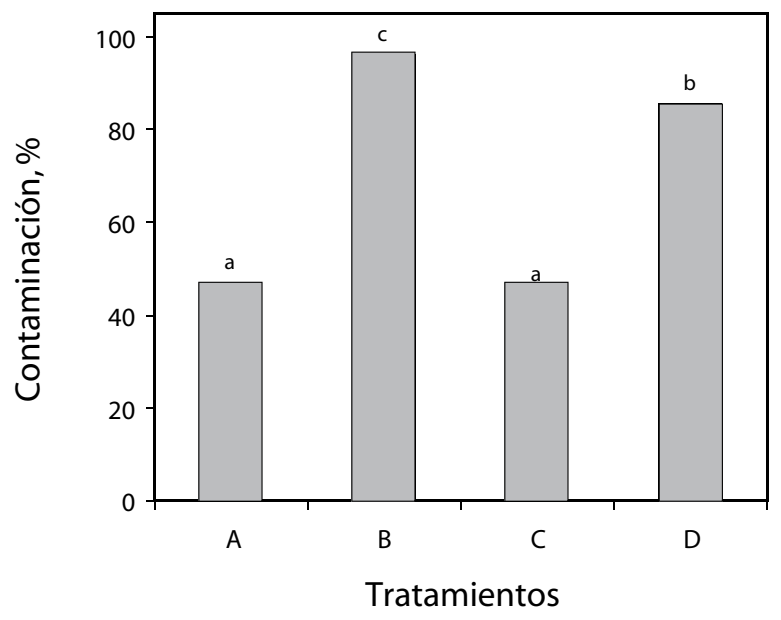

Figura 1. Efecto de la concentración de hipoclorito de sodio y de Tween 20 empleado como tensoactivo en la desinfección superficial de cariopses de Spartina argentinensis. A. Hipoclorito de sodio 1,5\% mas Tween 20. B. Hipoclorito de sodio 1,5\% sin Tween 20. C. Hipoclorito de sodio 2,5\% con Tween 20. D. Hipoclorito de sodio 2,5\% sin Tween 20. (n=5). Promedios seguidos por igual letra no son estadísticamente diferentes entre si según Duncan ( $<<0,05)$.

Figure 1. Effect of sodium hypochlorite concentrations and Tween 20 as humectant on superficial disinfection of caryopses of Spartina argentinensis. A. $1.5 \%$ sodium hypochlorite plus Tween 20. B. $1.5 \%$ sodium hypochlorite. C. $2.5 \%$ sodium hypochlorite plus Tween 20.D. 2.5\% sodium hypochlorite. Means followed by the same letter are not statistically different according to Duncan $(p<0.05)$. 


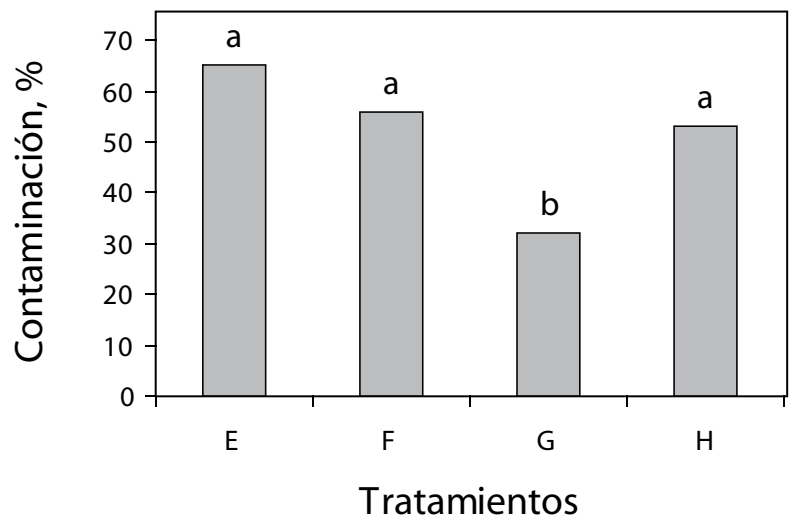

Figura 2. Efecto de los diferentes tratamientos sobre el porcentaje de contaminación de cariopses de Spartina argentinensis. E. 1 min en etanol $90^{\circ}$ y 20 min de inmersión en hipoclorito de sodio 2,5\% con Tween 20. F. Igual a E sin etanol. G. 1 min en etanol $90^{\circ}$ y 30 min de inmersión en hipoclorito de sodio $2.5 \%$ con Tween 20 . H. ídem G, sin etanol. Promedios seguidos por igual letra no son estadísticamente diferentes entre si según Duncan $(\mathrm{p}<0,05)$.

Figure 2. Effect of different treatments on surface contamination of caryopses of Spartina_argentinensis. E. Ethanol $90^{\circ}$ for $60 \mathrm{~s}$ and $20 \mathrm{~min}$ in $2.5 \%$ sodium hypochlorite plus Tween 20. F. Similar to E, but without ethanol. G. Ethanol $90^{\circ}$ for $60 \mathrm{~s}$ and $30 \mathrm{~min}$ in $2.5 \%$ sodium hypochlorite plus Tween 20. H. Similar to G, but without ethanol. Means followed by the same letter are not statistically different according to Duncan $(p<0.05)$.

La misma vía de regeneración de vástagos fue previamente informada para S. alterniflora, $S$. cynosuroides y S. patens (Wang et al., 2003; Li et al., 1995, 1996). En otras especies, ej. Eragrostis curvula, y utilizando el mismo explante, la regeneración de vástagos ocurrió vía embriogénica (Echenique et al., 2001) y en Bouteloua gracilis, la regeneración de vástagos se produjo tanto por vía organogénica como embriogénica (Agudo-Santacruz et al., 2000).

De las concentraciones hormonales utilizadas para la regeneración de vástagos, el medio $\mathrm{V} 2$ con 0,5 mg.L $\mathrm{L}^{-1}$ de BAP favoreció la mayor respuesta de los explantes, puesto que $20 \%$ de los callos regeneraron vástagos. En el medio V1, con 0,25 $\mathrm{mg} \cdot \mathrm{L}^{-1}$ de BAP, los porcentajes de respuestas fueron inferiores a $12 \%$. Si bien el porcentaje de callos que regeneraron vástagos fue bajo, cada callo diferenció múltiples vástagos, aumentando la eficiencia de regeneración.

La regeneración de raíces se indujo favorablemente con $0,50 \mathrm{mg} \cdot \mathrm{L}^{-1}$ de ANA. Las plantas regeneradas se separaron y se transfirieron a una mezcla de suelo (30\% vermiculita-70\% tierra) en invernadero.

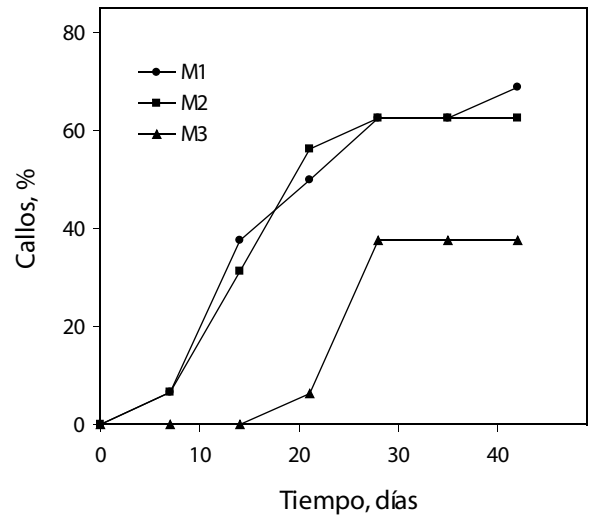

Figura 3. Efecto de distintos medios de cultivo sobre el porcentaje de producción de callos de Spartina argentinensis. $\mathrm{M} 1=0,5 \mathrm{mg} \cdot \mathrm{L}^{-1}$ de $2,4-\mathrm{D} ; 0,05 \mathrm{mg} \cdot \mathrm{L}^{-1}$ de BAP y $1 \mathrm{mg} \cdot \mathrm{L}^{-1}$ de ANA. M2 $=0,5 \mathrm{mg} \cdot \mathrm{L}^{-1}$ de 2,4-D; $1 \mathrm{mg} \cdot \mathrm{L}^{-1}$ de AIA. $\mathrm{M} 3=0,5 \mathrm{mg} \cdot \mathrm{L}^{-1}$ de $2,4-\mathrm{D}$ y $0,05 \mathrm{mg} \cdot \mathrm{L}^{-1}$ de BAP. BAP = 6-bencil amino purina; ANA = ácido naftalén acético; AIA = ácido indol acético; 2,4-D = ácido dicloro fenoxi acético.

Figure 3. Effect of different media on the percentage of callus production of Spatina argentinensis. $M 1=0.5$ $m g \cdot L^{-1} 2,4-D, 0.05 \mathrm{mg} \cdot \mathrm{L}^{-1} B A$, and $1 \mathrm{mg} \cdot \mathrm{L}^{-1} \mathrm{NAA} . \mathrm{M} 2=$ $0.5 \mathrm{mg} \cdot \mathrm{L}^{-1}$ and $2,4-D, 1 \mathrm{mg} \cdot \mathrm{L}^{-1}$ IAA. M3 $=0.5 \mathrm{mg} \cdot \mathrm{L}^{-1} 2,4-$ $D$, $0.05 \mathrm{mg} \cdot \mathrm{L}^{-1} B A . B A=6$-benzyl-adenine $; N A A=\alpha$ naphtaleneacetic acid; IAA = indole-3-acetic acid; 2,4-D =2,4-dichlorophenoxyacetic acid. 


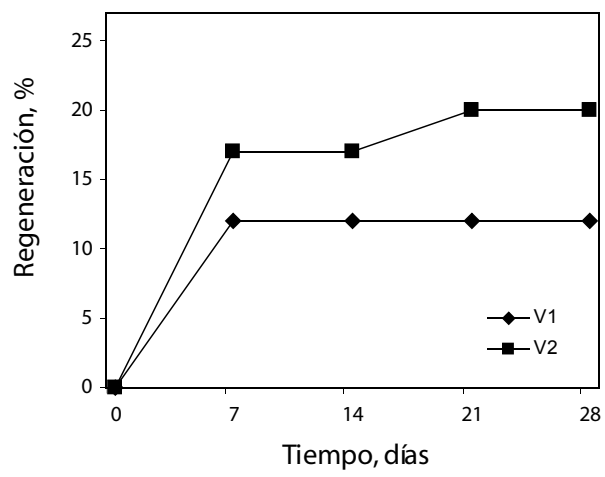

Figura 4. Variación del percentage de regeneración de vástagos de Spartina argentinensis. V1, 0,25 mg $\cdot \mathrm{L}^{-1} \mathrm{BAP}$ (6-bencil amino purina) y V2, 0,5 $\mathrm{mg} \cdot \mathrm{L}^{-1} \mathrm{BAP}$.

Figure 4. Percentage of Spartina argentinensis shoot regeneration using medium $V, 0.25 \mathrm{mg} \cdot \mathrm{L}^{-1} \mathrm{BP}$ (6-benzyladenine) and $V 2,0.5 \mathrm{mg} \cdot \mathrm{L}^{-1} \mathrm{BP}$.

La metodología de desinfección de cariopses estudiada se podría extender a otras especies que presenten altos porcentajes de contaminación fúngica, debido a que permite utilizar el tratamiento combinado de $\mathrm{NaOCl}$ y etanol, que presentan baja toxicidad, a diferencia de otros que utilizan cloruro de mercurio (Wang et al., 2003).

Este trabajo es la primera mención de regeneración de plantas de $S$. argentinensis utilizando cultivo in vitro de cariopses maduros y constituye la etapa inicial para la obtención de variantes somaclonales. De esta forma se espera poder obtener líneas mejoradas en busca de cultivares con una mejor aptitud ganadera. Del mismo modo, estos protocolos de regeneración pueden aplicarse a otras especies de gramíneas, comunes en pastizales naturales.

\section{Resumen}

Se desarrolló un protocolo de desinfección y regeneración in vitro de Spartina argentinensis. El menor porcentaje de contaminación se obtuvo tratando los cariopses por $60 \mathrm{~s}$ en etanol $90^{\circ}$ y 20 min de inmersión en hipoclorito de sodio al 2,5\% con Tween 20. La inducción de callos se realizó en medio Murashige y Skoog (MS) suplementado con $0,5 \mathrm{mg} \cdot \mathrm{L}^{-1}$ de ácido diclorofenoxi acético $(2,4-\mathrm{D})$ y $1 \mathrm{mg} \cdot \mathrm{L}^{-1} \mathrm{de}$

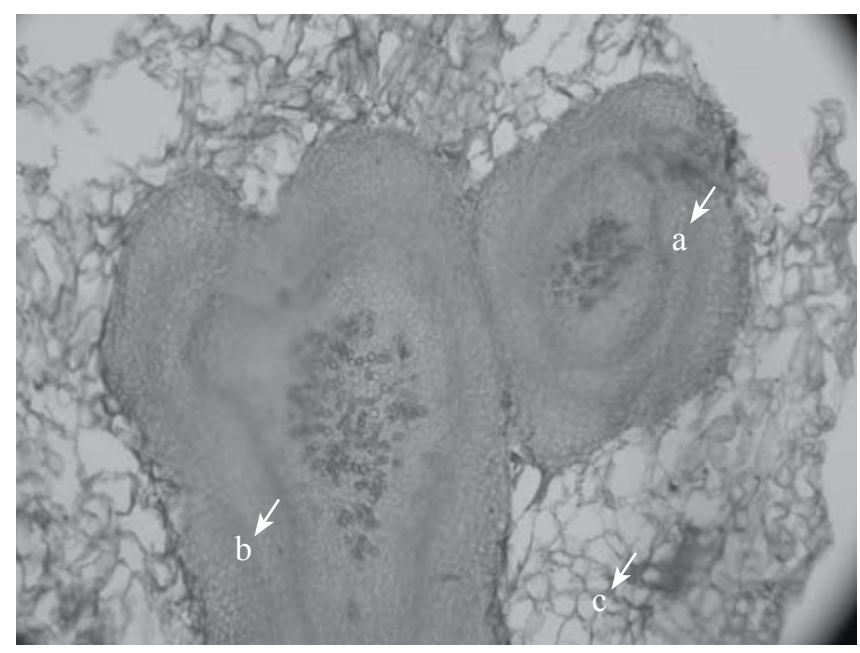

Figura 5. Corte de callo de Spartina argentinensis de 31 días obtenido de cariopses maduros en medio V1, 0,25 $\mathrm{mg} \cdot \mathrm{L}^{-1}$ BAP. Las flechas señalan la formación de vástagos, rudimento de hoja (a), cordón precambial (b) y callo (c). Barra $=10 \mu$.

Figure 5. Cross section of a 31 day old callus of Spartina argentinensis, using caryopses as explant, on V1 $0.25 \mathrm{mg} \cdot \mathrm{L}^{-}$ ${ }^{1}$ BP ( 6-benzyl-adenine) as regeneration media. Arrows show shoot regeneration. a, leaf rudiment; $b$, precambial tissue, and c, callus. Bar $=10 \mu$. 
ácido indol acético (AIA). La mayor (20\%) regeneración de vástagos se logró con igual base salina y $0,25 \mathrm{mg} \cdot \mathrm{L}^{-1}$ de bencilamino purina (BAP). Se utilizó $0,025 \mathrm{mg} \cdot \mathrm{L}^{-1}$ de ácido naftalen acético para la regeneración de raíces. Las plantas se regeneraron vía organogénesis. Este protocolo es la primera mención de regeneración de plantas de $S$. argentinensis utilizando cultivo in vitro y constituye la etapa inicial para obtener variantes somaclonales. $\mathrm{La}$ metodología de desinfección se puede hacer extensiva a otras especies.

Palabras clave: Organogenesis, regeneracion in vitro, Spartina.

\section{Literatura citada}

Agudo-Santacruz, G., J.L. Cabrera-Ponce, V. Olalde-Portugal, M. Sánchez-González, Márquez-Guzmán, and L. Herrera-Estrella. 2001. Tissue culture and plant regeneration of blue Grama grass, Bouteloua gracilis (H.B.K.) Lag. Ex Steud. Plant 37:182-189.

Dizeo de Strittmater, C.1979. Modificación de una técnica de coloración safranina- fast green. Bol. Soc. Arg. Botánica 18:121-122.

Dutta Grupta, S., and B. Conger.1999. Somatic Embriogenesis and plant regeneration from suspension cultures of switchgass. Crop Science 39:243-247.

Echenique, V., M. Díaz, P. Polci, and L. Mroginsky. 2001. Embryogenic cell suspensions from different explants and cultivars of Eragrostis curvula (Schrad.) Nees. Biocell 25:131-138.

Feldman, S. R. 2003. Ecología de Spartina argentinensis Parodi. Crecimiento y desarrollo de la planta y efecto del fuego sobre sus poblaciones y comunidades Tesis Doctoral. Facultad de Ciencias Exactas, Físicas y
Naturales, Universidad Nacional de Córdoba, Córdoba, Argentina. 182 pp.

Feldman, S. R.; N. S. Pioli y J. P. Lewis. 2004. Caracterización de los propágulos de origen sexual de Spartina argentinensis Parodi. Revista de Investigación, Facultad de Ciencias Agrarias, Universidad Nacional de Rosario (Argentina) 4:69-73.

Johansen, D.A. 1940. Plant Microtechnique, Mac Graw Hill. NY, USA. 523 pp.

KotharI, S.L., K. Satish, R.K. Vishnoi, A. Kothari, and N.W. Kazuo. 2005. Appications of biotecnology for improvement of millet crops: Review of progress and future prospects. Plant Biotechnology 22:81-88.

Larkin, P., and W. Scowcroft. 1981. Somaclonal variation a novel source of variability from cell culture for plant improvement. Theoretical and Applied Genetics 60:197-214.

Li, X., D.M., J.A. Seliskar, J. Moga, and J.L. Gallagher. 1995. Plant regeneration from callus cultures of salt marsh hay, Spartina patens, and its cellular-based salt tolerance. Aquatic Botany 51:103-113.

Li, X., D.M., and J.L. Gallagher. 1996. Tissue culture and plant regeneration of big cordgrass, Spartina cynosuroides: implications for wetland restoration. Wetlands 16:410-415.

Murashige, T., and F. Skoog. 1962. A revised medium for rapid growth and bioassays with tobacco tissue cultures. Physiologia Plantarum 15:473-497.

Mroginski, L.A. y W.M. Roca. 1991. Establecimiento de cultivos de tejidos vegetales in vitro. Paginas 19-40. En: Cultivo de tejidos en la agricultura: fundamentos y aplicaciones. CIAT. Cali, Colombia.

Wang, J., D.M. Seliskar, and J.L. Gallagher. 2003. Tissue culture and plant regeneration of Spartina alterniflora: implications for wetland restoration. Wetlands 23:386-393. 